\title{
Evaluation of A New Mixed-Phase Cloud Microphysics Parameterization with the NCAR Climate Atmospheric Model (CAM3) and ARM Observations
}

Fourth Quarter 2007 ARM Metric Report

September 2007

Xiaohong Liu and Steven J. Ghan

Pacific Northwest National Laboratory

Richland, Washington

Shaocheng Xie, James Boyle, and Stephen A. Klein

Lawrence Livermore National Laboratory

Livermore, California

Work supported by the U.S. Department of Energy, Office of Science, Office of Biological and Environmental Research 


\section{Summary}

Mixed-phase clouds are composed of a mixture of cloud droplets and ice crystals. The cloud microphysics in mixed-phase clouds can significantly impact cloud optical depth, cloud radiative forcing, and cloud coverage. However, the treatment of mixed-phase clouds in most current climate models is crude and the partitioning of condensed water into liquid droplets and ice crystals is prescribed as temperature dependent functions. In our previous 2007 ARM metric reports a new mixed-phase cloud microphysics parameterization (for ice nucleation and water vapor deposition) was documented and implemented in the NCAR Community Atmospheric Model Version 3 (CAM3). The new scheme was tested against the Atmospheric Radiation Measurement (ARM) Mixed-phase Arctic Cloud Experiment (M-PACE) observations using the single column modeling and short-range weather forecast approaches. In this report this new parameterization is further tested with CAM3 in its climate simulations. It is shown that the predicted ice water content from CAM3 with the new parameterization is in better agreement with the ARM measurements at the Southern Great Plain (SGP) site for the mixed-phase clouds. 


\section{Contents}

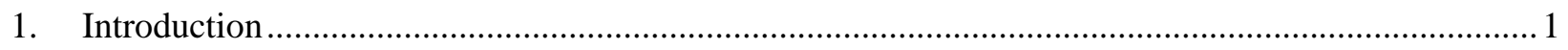

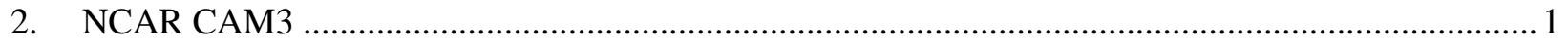

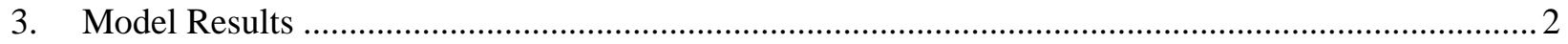

3.1 Comparisons Between the Standard and the Modified CAM3 .............................................. 2

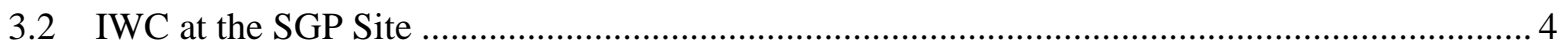

3.3 IWC Comparison with Satellite Data................................................................................. 5

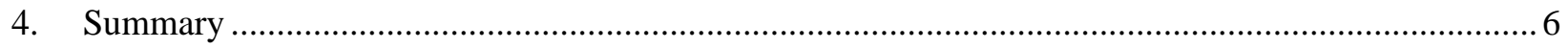

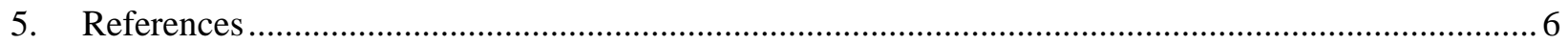

\section{Figures}

1 Annual zonal mean latitude versus pressure cross sections of temperature (K), specific humidity $\left(\mathrm{g} \mathrm{kg}^{-1}\right)$, cloud cover (\%), and cloud ice mass mixing ratio $\left(\mathrm{mg} \mathrm{kg}^{-3}\right)$ by the standard CAM (simulation REF) (left panel) and by CAM with the new scheme (simulation ICE) (middle panel), and the difference ICE - REF (right panel).

2 Ice water content profiles from observation data at the SGP site, and from the CAM simulations REF (sold line) and ICE (dotted line) ............................................................................. 4

3 Annual and zonal mean ice water content $\left(\mathrm{mg} \mathrm{m}^{-3}\right)$ predicted from (a) the simulation ICE and (b) simulation REF and that measured by (c) the Aura MLS instrument. 


\section{Introduction}

Mixed-phase clouds are composed of a mixture of cloud droplets and ice crystals. A large percentage of the earth's precipitation (>50\%) originates in the ice phase [Heymsfield et al., 2005]. The partitioning of condensed water into liquid droplets and ice crystals in mixed-phase clouds varies with time and cloud properties besides temperature, which can significantly impact the cloud optical depth, cloud radiative forcing, and cloud coverage [Fowler and Randall, 1996; Gregory and Morris, 1996]. However, the treatment of mixed-phase clouds in most current climate models is often oversimplified due to a lack of complete understanding of detailed microphysics in mixed-phase clouds. For example, the ice formation mechanisms in mixed-phase clouds are not well understood [e.g., Fridland et al., 2007]. The latest version of the NCAR Community Atmospheric Model (CAM3) still assumes a temperature-dependent function to partition the condensed water into liquid and ice in mixed-phase clouds which can limit its ability to accurately simulate the cloud phase and structure and their radiative properties. The effective radii of cloud droplets and ice crystals in CAM3 are simply prescribed. Thus, the aerosol-cloud-radiation interactions can not be represented.

A two-moment cloud microphysics scheme is introduced to CAM3 to provide a realistic representation of ice nucleation, crystal growth and droplet evaporation in the mixed-phase clouds [Liu et al., 2007]. This scheme includes detailed treatment of ice nucleation [Liu and Penner, 2005] and vapor deposition on ice crystals [Rotstayn et al., 2000]. Thus, the repartitioning of total water into liquid and ice in mixed-phase clouds as a function of temperature in the default CAM3 is removed. The effective radii of cloud droplets and ice crystals which are used in the radiation and gravitational settlement calculations are now calculated from model predicted mass and number of cloud droplets and ice crystals rather than prescribed as a function of temperature as in the default CAM3. In our previous ARM Metrics Reports [Liu and Ghan, 2007; Liu et al., 2007; Xie et al., 2007] the detailed description of this new scheme and its performance in CAM3 were documented. The new scheme has been evaluated against ARM Mixed-phase Arctic Cloud Experiment (M-PACE) observations under the CAM single column modeling framework (SCAM) and the DOE CCPP-ARM Parameterization Testbed (CAPT), which uses a short-range weather forecast approach to test climate models. It was found that the new scheme allows a more realistic simulation of the cloud phase and structure and the partitioning of condensed water into liquid droplets than the standard CAM simulations. In addition the new scheme leads to an improved simulation of cloud fraction and the surface and top of the atmosphere longwave radiation fluxes in CAM3 weather forecasts.

In this report, the above new microphysics scheme is further tested with CAM3 in its climate simulations. Simulated ice water content (IWC) is compared with the ARM observations at the Southern Great Plain (SGP) site as well as with the satellite retrievals. It is shown that CAM with the new scheme has a better predictions of IWC in the mixed-phase clouds than that from the standard CAM3.

\section{NCAR CAM3}

The NCAR CAM3 is the atmospheric component of the Community Climate System Model (CCSM, Collins et al., 2006). The treatment of cloud condensation and microphysics in CAM3 [Boville et al., 2006] is based on Rasch and Kristjánsson [1998] as updated by Zhang et al. [2003] with separate prognostic equations for the liquid and ice-phase condensate. Even though each phase of water is 
transported separately, after advection, convective detrainment, and sedimentation, the liquid and ice are repartitioned according to a temperature dependent fraction of ice in total water $\left(f_{\mathrm{i}}\right)$

$$
0 \leq f_{i}=\frac{T-T_{\max }}{T_{\min }-T_{\max }} \leq 1
$$

where the bounds $T_{\min }$ and $T_{\max }$ are adjustable within a narrow range. The values in CAM3 are $-40^{\circ}$ and $-10^{\circ} \mathrm{C}$, respectively. In this way the CAM3 avoids the representation of a variety of processes (e.g., the Bergeron-Findersen process, ice nucleation, etc.) in mixed-phase clouds.

A two-moment ice-phase microphysics scheme has been introduced to the CAM3 [Liu et al., 2007], in which cloud droplet and ice crystal number concentration are predicted. Thus the effective radii of cloud droplets and ice crystals which are used in the radiation and gravitational settlement calculations are now calculated from model predicted mass and number rather than prescribed as a function of temperature. Ice nucleation mechanisms include homogeneous ice nucleation on sulfate aerosol and heterogeneous immersion nucleation on soot particles in ice clouds with temperature less than $-35^{\circ} \mathrm{C}[\mathrm{Liu}$ and Penner, 2005], contact freezing of cloud droplets through Brownian coagulation with insoluble IN (assumed to be mineral dust), and deposition/condensation nucleation [Meyers et al., 1992]. Secondary ice production between -3 and $-8{ }^{\circ} \mathrm{C}$ is included for Hallet-Mossop multiplication.

We added the Rotstayn et al. [2000] scheme in CAM3 to represent the conversion of cloud liquid water to ice in the mixed-phase clouds via the Bergeron-Findeisen process (in which ice crystals grow through vapor deposition at the expense of evaporating cloud droplets). The deposition growth of ice crystals is proportional to the number density of ice crystals. The vapor deposition, combined with a treatment of riming of droplets on ice crystals in CAM3 [Rasch and Kristjánsson, 1998], permits explicit treatment of the Bergeron-Findeisen process, rather than simply diagnosing the condensate phase from temperature.

\section{Model Results}

The simulations with the standard CAM3 (simulation REF) and with the modified CAM3 with the new microphysics scheme (simulation ICE) were conducted at $2^{\circ} \times 2.5^{\circ}$ horizontal resolution with 26 vertical levels over a period of 3 years after an initial spin-up of 4 months using climatological (19502000) sea surface temperatures . The aerosol climatology prescribed in the CAM3 [Collins et al., 2001] is used. Results from the last 3 years are presented below.

\subsection{Comparisons Between the Standard and the Modified CAM3}

Figure 1 shows the annual average zonal mean latitude versus pressure cross sections of temperature, specific humidity, cloud cover, and ice water mixing ratio for the simulation REF and ICE. Specific humidity in the ICE simulation is reduced in the tropical convective regions in the lower and middle troposphere and in some regions of the mid-latitudes, but is increased elsewhere. The largest relative increase occurs in the tropical tropopause and lower stratosphere regions (by 50\%) above $200 \mathrm{hPa}$. Correspondingly cloud cover is increased near the tropical tropopause $(\sim 100 \mathrm{hPa})$ and over polar regions. 
The higher cloud cover (by 20-30\%) near the tropical tropopause is due to the formation of subvisible cirrus clouds from ice nucleation, while cloud cover there in the standard CAM3 is underestimated [Boville et al., 2006]. Wang et al. [1996] found that subvisible cirrus clouds occurred $>45 \%$ of the time just below the tropical tropopause in the Stratospheric Aerosol and Gas Experiment II profiles. These subvisible cirrus clouds contribute to a temperature increase due to radiation heating, which reduces the cold tropopause bias in the standard CAM3 by $1-2 \mathrm{~K}$. The zonal mean maxima of cloud ice mixing ratio are increased significantly in the ICE simulation. Above these maxima, the cloud ice mixing ratio is slightly decreased.
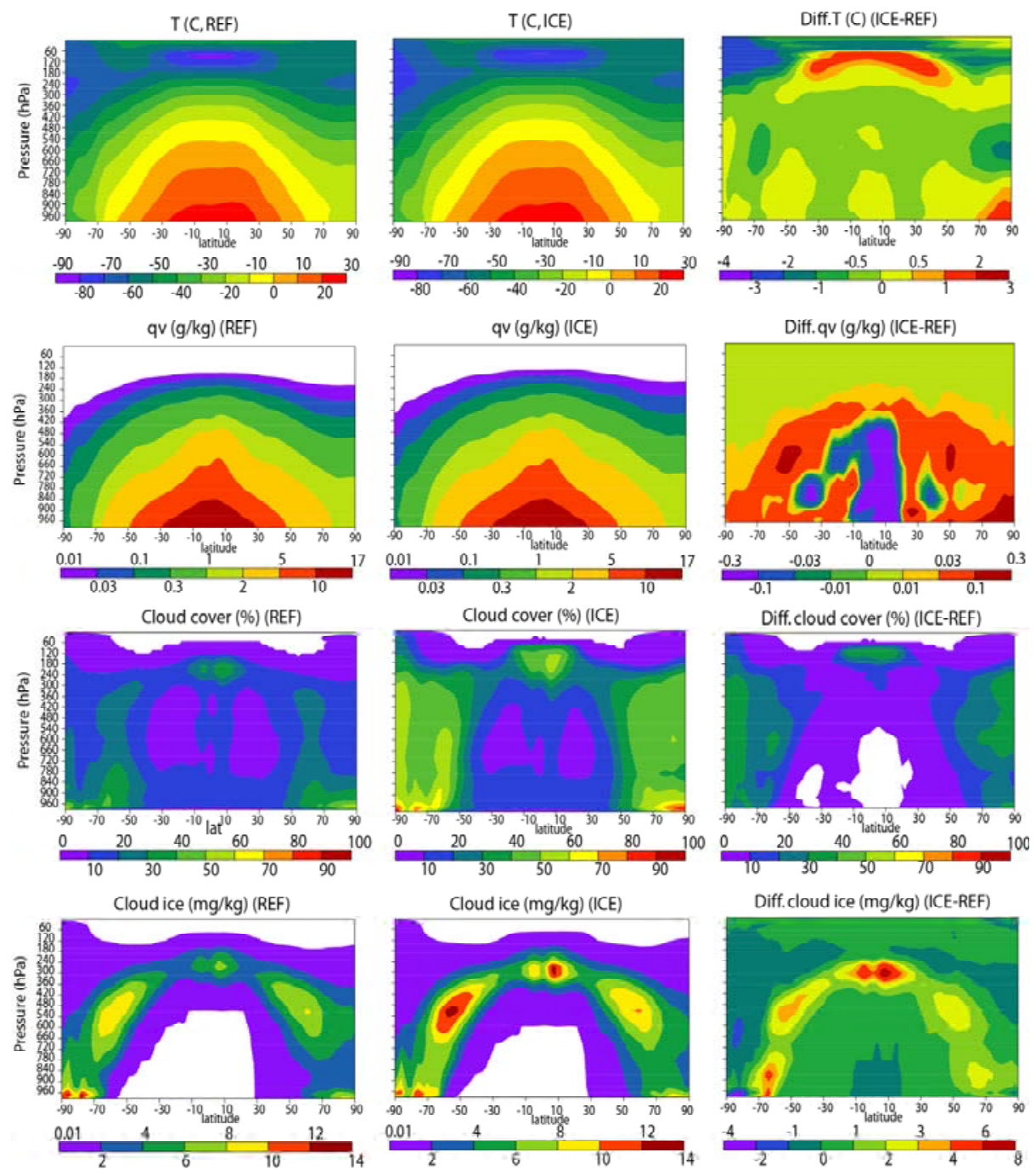

Figure 1: Annual zonal mean latitude versus pressure cross sections of temperature $(\mathrm{K})$, specific humidity $\left(\mathrm{g} \mathrm{kg}^{-1}\right)$, cloud cover (\%), and cloud ice mass mixing ratio $\left(\mathrm{mg} \mathrm{kg}^{-3}\right)$ by the standard CAM (simulation REF) (left panel) and by CAM with the new scheme (simulation ICE) (middle panel), and the difference ICE - REF (right panel). 


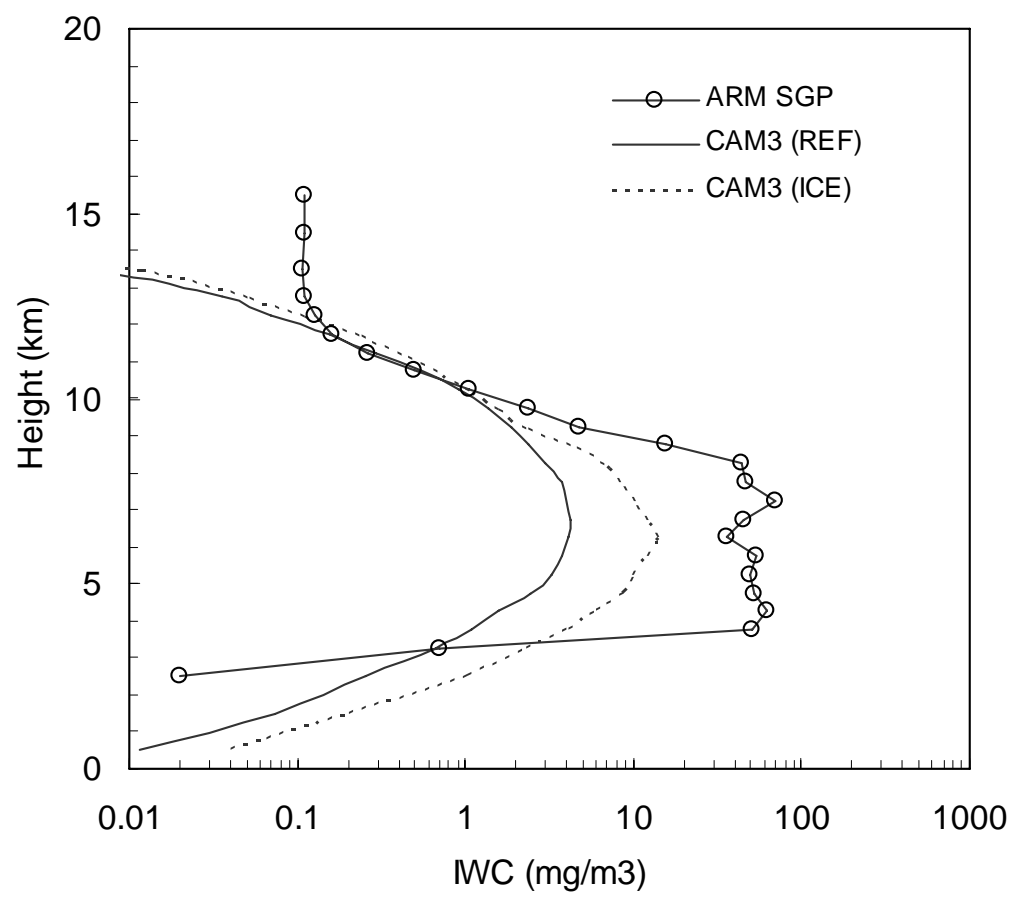

Figure 2: Ice water content profiles from observation data at the SGP site, and from the CAM simulations REF (sold line) and ICE (dotted line).

\subsection{IWC at the SGP Site}

One of the difficulties in using radar/lidar/radiometer observations to validate models is that these observations are often single-point measurements, and may not be representative of cloud properties predicted from the global climate models with larger grid sizes (100-500 km). Seo and Liu [2006] combined surface remote sensing and satellite measurements to derive three dimensional IWC distributions in a $10^{\circ} \times 10^{\circ}$ area $\left(31.6-41.6^{\circ} \mathrm{N}\right.$ and $\left.92.5-102.5^{\circ} \mathrm{W}\right)$ near the Atmospheric Radiation Measurement (ARM) Southern Great Plain (SGP) site. Currently only the ice water retrievals for the March 2000 SGP Intensive Operation Period are available. We averaged the ARM IWC data temporally and horizontally to produce the monthly mean vertical profile of IWC. In order to compare with measured data, we also averaged the model grid mean IWC horizontally over the same area $\left(10^{\circ} \times 10^{\circ}\right)$. Figure 2 shows the IWC profiles from ARM data, and from the CAM simulations REF and ICE. Both CAM simulations broadly capture the IWC maximum between $3 \mathrm{~km}$ and $8 \mathrm{~km}$ for the mixed-phase clouds. However, the standard CAM3 under-predict the data by a factor of 10. The simulation ICE improves the comparison. It is noted that the IWC retrievals also exist large uncertainties [Seo and Liu, 2006]. 

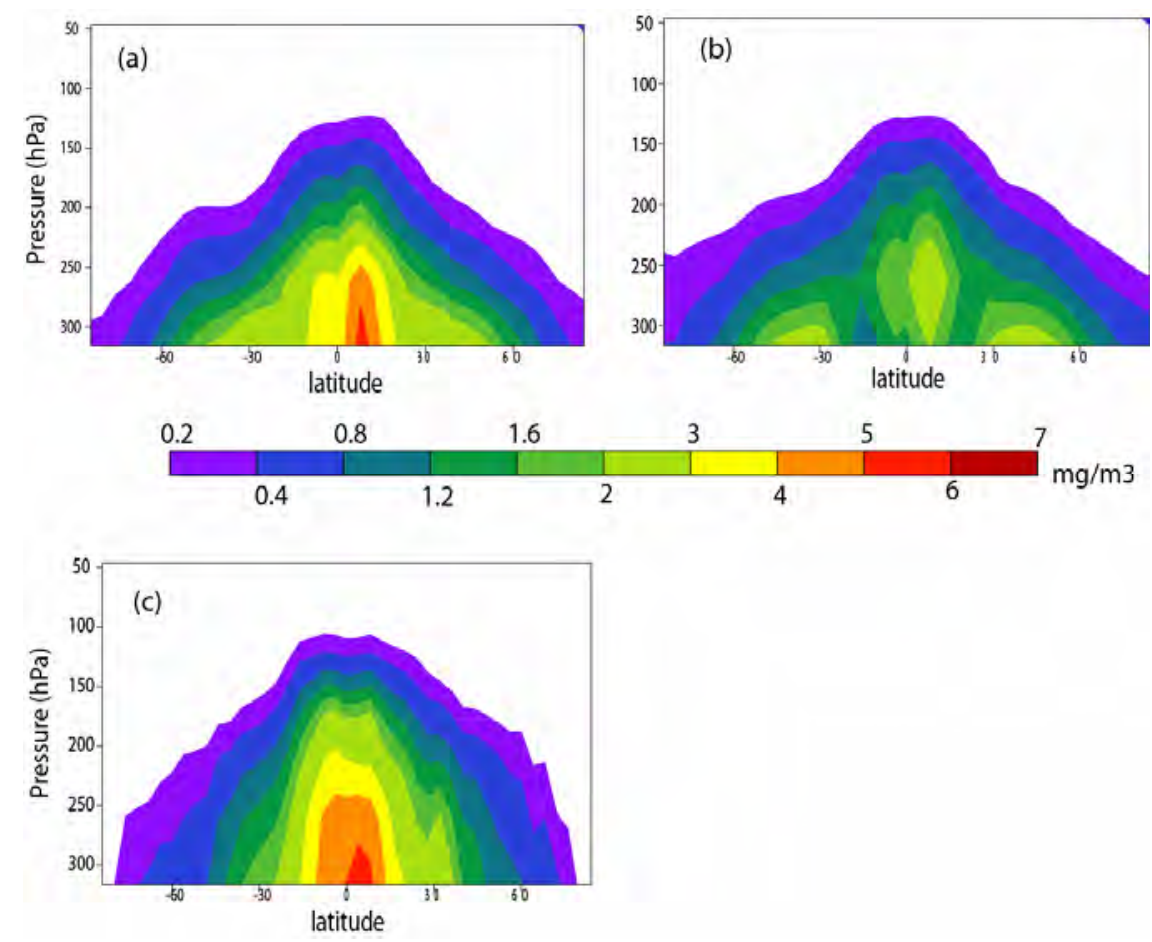

Figure 3: Annual and zonal mean ice water content $\left(\mathrm{mg} \mathrm{m}^{-3}\right)$ predicted from (a) the simulation ICE and (b) simulation REF and that measured by (c) the Aura MLS instrument.

\subsection{IWC Comparison with Satellite Data}

The NASA Earth Observing System (EOS)'s Microwave Limb Sounder (MLS) [Waters et al., 1999] onboard the Aura satellite (launched on July 15, 2004) has five radiometers measuring microwave emissions from the Earth's atmosphere to retrieve chemical composition, water vapor, temperature and cloud ice. The MLS ice water content consists of data from the upper troposphere and lower stratosphere (from $316 \mathrm{hPa}$ to $46 \mathrm{hPa}$ ) and have a near-global $\left(82^{\circ} \mathrm{S}-82^{\circ} \mathrm{N}\right.$ ) coverage. The estimated uncertainty in the IWC measurements is approximately 1.2, 1.8 and $3 \mathrm{mg} \mathrm{m}^{-3}$ at 100,147 , and $215 \mathrm{hPa}$, respectively [Li et al., 2005]. The data used here for comparison are monthly mean IWCs from September 2004 to August 2005 averaged with $4^{\circ}$ (latitude) $\times 8^{\circ}$ (longitude) horizontal resolution, and thus have an uncertainty on the order of $0.1 \mathrm{mg} \mathrm{m}^{-3}$ due to time and spatial averages [Li et al., 2005]. For comparison, were gridded the CAM3 data to the same MLS horizontal and vertical resolution.

Figure 3 shows the annual and zonal mean IWC predicted from simulation ICE and REF as compared with the MLS data. The predicted IWC from the modified CAM (simulation ICE) is more consistent with the MLS Aura data in the upper troposphere than the standard CAM prediction. Although the standard CAM generally reproduces the horizontal IWC distribution patterns with maxima in the Western Pacific, the Indian Ocean, and over Central Africa and South America, it predicts too little IWC by as much as a factor of 4 in tropical regions [ $\mathrm{Li}$ et al., 2005]. We note that our modified CAM (i.e., ICE) may still underestimate IWC at levels above $\sim 200 \mathrm{hPa}$ in the tropics by a factor of 2-3, since the MLS IWC is distributed to higher altitudes there. Moreover, the MLS IWC has a more rapid reduction from the tropics towards the two poles than does the model (i.e., lower MLS IWCs at polar regions). 


\section{Summary}

In this report the new cloud microphysics scheme is further tested in CAM3 climate simulations. The new scheme leads to the improvement of the cloud fraction and reduction of temperature bias in the tropical tropopause. The predicted ice water content in the CAM3 with the new scheme is in better agreement with the ARM observation at the SGP site for the mixed-phase clouds and with the Aura MLS data than that in the standard CAM3.

\section{References}

Boville, B. A., P. J. Rasch, J. J. Hack, and J. R. McCaa, Representation of clouds and precipitation processes in the Community Atmosphere Model version 3 (CAM3), J. Climate, 19, 2184-2198, 2006.

Collins, W. D. et al., The formulation and atmospheric simulation of the Community Atmosphere Model Version 3 (CAM3), J. Climate, 19, 2144-2161, 2006.

Collins, W. D. et al., Simulating aerosols using a chemical transport model with assimilation of satellite aerosol retrievals: Methodology for INDOEX, J. Geophys. Res., 106, 7313-7336, 2001.

Fowler L.D., and D. A. Randall, Liquid and ice cloud microphysics in the CSU general circulation model.2. Impact on cloudiness, the earth's radiation budget, and the general circulation of the atmosphere, J. Climate, 9, 530-560, 1996.

Fridlind, A. M. et al., Ice properties of single-layer stratocumulus during the Mixed-Phase Arctic Cloud Experiment 2 (M-PACE): Part II, Model results, submitted to J. Geophys. Res., 2007.

Gregory, D., and D. Morris, The sensitivity of climate simulations to the specification of mixed phase clouds, Climate Dyn., 12, 641-651, 1996.

Heymsfield, et al., The Ice in Clouds Experiment - Research Plan, Scientific Overview Document, National Center for Atmospheric Research, September 2, 2005. (http://www.mmm.ucar.edu/events/ice05/images/ICE-SOD-050902.pdf)

Li, J.-L., and Coauthors, 2005: Comparisons of EOS MLS cloud ice measurements with ECMWF analyses and GCM simulations: Initial results. Geophys. Res. Lett., 32, L18710, doi:101029/2005GL023788.

Liu, X., and J. E. Penner, Ice nucleation parameterization for global models, Meteorologische Zeitschrift, 14, No.4, 499-514, 2005.

Liu, X. J. E. Penner, S. Ghan, and M. Wang (2007), Inclusion of ice microphysics in the NCAR Community Atmospheric Model version 3 (CAM3), J. Climate, 20, 4526-4547.

Liu, X, and S. Ghan, 2007: Mixed-phase cloud microphysics for global climate models.” First Quarter 2007 ARM metric report, available from http://www.arm.gov/science/metrics.stm. 
Liu, X, S. Ghan, and S. Xie. 2007: "Evaluation of mixed-phase cloud microphysics parameterizations with the NCAR single column climate model (SCAM) and ARM observations.” Second Quarter 2007 ARM metric report, available from http://www.arm.gov/science/metrics.stm.

Meyers, M. P., P. J. DeMott, and W. R. Cotton, New primary ice nucleation parameterizations in an explicit cloud model, J. Appl. Meteor., 31, 708-721, 1992.

Rasch, P. and J. E. Kristjánsson, A comparison of the CCM3 model climate using diagnosed and predicted condensate parameterizations, J. Climate, 11, 1587-1614, 1998.

Rotstayn, L. D., B. F. Ryan, and J. J. Katzfey, A scheme for calculation of the liquid fraction in mixedphase stratiform clouds in large-scale models, Mon. Wea. Rev., 128, 1070-1088, 2000.

Seo, E.-K., and G. Liu, 2006: Determination of 3-D cloud ice water contents by combining multiple data sources from satellite, ground radar, and a numerical model. J. Appl. Meteorol. Clim., 45, 1494-1504.

Wang, P.-H., P. Minnis, M. P. McCormick, G. S. Kent, G. K. Yue, D. F. Young, and K. M. Skeens, 1996: A 6-year climatology of cloud occurence frequency from Stratospheric Aerosol and Gas experiment II observations (1985-1990). J. Geophys. Res., 101, 29 407-29 429.

Waters, J. W., and Coauthors, 1999: The UARS and EOS Microwave Limb Sounder experiments. J. Atmos. Sci., 56, 194-218.

Xie, S., J. Boyle, S. Klein, X. Liu and S. Ghan, Evaluation of Mixed-Phase Cloud Parameterizations in Short-Range Weather Forecasts with CAM3 and AM2 for Mixed-Phase Arctic Cloud Experiment, Third Quarter 2007 ARM metric report, available from http://www.arm.gov/science/metrics.stm.

Zhang, M., W. Lin, C. B. Bretherton, J. J. Hack, and P. J. Rasch, A modified formulation of fractional stratiform condensation rate in the NCAR Community Atmosphere Model (CAM2), J. Geophys. Res., 108, 4035, doi:10.1029/2002JD002523, 2003. 